\title{
Effect of Tylenchulus semipenetrans inoculum levels on its development, reproduction potential, and damage to infected-Volkamariana seedlings
}

\author{
Mahfouz M. M. Abd-Elgawad*, Faika F. H. Koura*, Ahmed E. Abd El-Wahab**, \\ Hassan Abd-El-Khair*, Sayed A. Montasser**, and Moustafa M. A. Hammam* \\ Phytopathology Department, National Research Center, El-Tahrir St., Dokki 12622, Giza, Egypt. \\ ** Department of Agricultural Zoology and Nematology, Factulty of Agriculture, Al-Azhar \\ University, Egypt.
}

\section{Abstract}

Six inocula 0, 5000, 10000, 15000, 20000 and 25000 second stage juveniles $\left(\mathrm{J}_{2}\right)$ and males/pot of $T$. semipenetrans were tested on 1.5-year-old nematode-free seedlings of Citrus volkameriana. The inoculated seedlings were grown in plastic pots containing about $5 \mathrm{Kg}$ of sterilized sandy clay soil (2:1) under greenhouse conditions for a year. Nematode reproduction and host growth were both affected by the initial inoculum levels. The maximum reduction percentage of shoot length $(38.3 \%)$, fresh $(25.9 \%)$, and dry $(44.7 \%)$ weight as well as root length $(36 \%)$ and fresh weight (30.5\%) were recorded at inoculum levels 20000, 20000, 15000, 25000 and $15000 \mathrm{~J}_{2}$ and males/seedling; respectively. On the other hand, the maximum nematode final population of $J_{2}$ and males (95515), females (1442), and eggmasses (820) were obtained at initial inoculum levels of 20000, 20000, and $15000 \mathrm{~J}_{2}$ and males/seedling; respectively. A negative relationship occurred between the nematode inoculum level and the rate of reproduction.

Key words: citrus, inoculum levels, Tylenchulus semipenetrans, Volkameriana.

\section{Introduction}

The citrus nematode, Tylenchulus semipenetrans Cobb, is distributed throughout the citrus-growing regions of the world, and often causes significant reductions in tree growth and yield (Duncan, 2005). In Egypt, different biotypes of the citrus nematode is wide spread in many orchards infecting several perennial crops but mainly in citrus groves (Afia, 1997; El-Nouby, 2002; Abd-Elgawad et al., 2010). Symptom severity (chlorosis, twig dieback, stunting, reduced fruit quality and quantity, and poor vigor) varies with tree age, nematode population size, grove management practices, and edaphic conditions in the grove (Kaplan and O'Bannon, 1981). Historically, citrus species and cultivars are mainly grafted on sour orange [Citrus aurantium (L.)] rootstocks in the Nile Valley and Delta. The citrus nematode-inoculation levels and the growth response of different citrus rootstocks have been studied by Ahmed (1974). He found that the potential growth of sour orange [Citrus aurantium (L.)] rootstock was progressively reduced, while the inoculum potential increased. El-Deeb (1995) used eight inocula of $T$. 
semipenetrans on sour orange rootstocks. These inocula were $0,200,500,1000$, 2000, 4000, 8000 and 16000 second stage juveniles $\left(J_{2}\right)$, respectively. He found that the reproduction factor of $T$. semipenetrans increased with the progressive increase in their initial population (Pi) up to level of $1000 \mathrm{~J}_{2} / 250$ gram soil in pots then decreased gradually, while $\mathrm{Pi}$ increased. Influence of $\mathrm{Pi}$ inocula on the growth response of both shoot and root system was observed. He found that the plant growth was highly affected by the high inocula of $T$. semipenetrans.

Recently, the growth and fruiting of citrus trees grown in newly reclaimed land in Egypt are adversely affected if trees are grafted on sour orange (Hafez, 2006); so many growers are shifting towards Volkameriana ( $C$. volkameriana Ten et Pas) as a rootstock. Yet, wide desert land reclamation is increasing the planting of citrus trees in light soils to which organic matter is added and seedlings from the valley is transplanted; conditions under which $T$. semipenetrans is likely to be a hazard to citrus production. The implication is that future tree growth and yield could be threatened by the nematode which may infest the newly established citrus groves via organic fertilizers, irrigation water, planting of nematode-infected citrus seedlings/young trees, contaminated machinery, and other sources that may harbor the nematodes (Abd-Elgawad et al., 2011). The sampling data collected disclosed the problem of widespread movement of citrus nematode-infested material onto such virgin groves (Abd-Elgawad and McSorley, 2009) but variable edaphic or environmental factors affect the nematode carrying capacity of the soil and root leading to different nematode-infestation levels. This research was initiated to determine the effects of different $T$. semipenetrans-inoculum levels on nematode development, reproduction potential, as well as damage to infected-Volkamariana seedlings.

\section{Materials and Methods}

Six inocula of $T$. semipenetrans-jjuveniles $\left(\mathrm{J}_{2}\right)$ and males in aqueous suspension were obtained by incubation (Young, 1954) of Yousefi Baladi [Citrus sinensis (L.) Osbeck] roots from a mature citrus orchard (Abd-Elgawad et al., 2011). The inocula were tested on 1.5-year-old nematode-free seedlings of $C$. volkamariana grown in plastic pots containing about $5 \mathrm{Kg}$ of sterilized sandy clay soil (2:1). A very careful standardization of different variables was taken into consideration: the seedlings should not differ in appearance, size and health to avoid problems from hidden factors that affect trees and nematodes independently. Because the citrus nematode is a mild pathogen that likely requires a huge range in population density to measure significant effects, different nematode inocula were tested. The seedlings were established for 6 months before initiating the inocula 0 , 5000, 10000, 15000, 20000 and 25000 nematodes $\left(\mathrm{J}_{2}+\right.$ males $) /$ seedling as initial nematode population $(\mathrm{Pi})$ in May 2011. The nematode suspension of each inoculum level was pipetted into five cores around the root system of a seedling and then immediately covered with wetted sandy soil. Eight replicates (seedlings) were used 
for each inoculum level treatment as well as the check. Pots were arranged in a randomized block design and seedlings were maintained on a greenhouse bench at 17 to $37^{\circ} \mathrm{C}$. All pots received similar treatments of nutrition during the experimental period (Ibrahim and Khaleef, 1997) and the citrus plants were watered as needed. One year after nematode inoculation, the citrus plants were uprooted. The numbers of $\mathrm{J}_{2}$ and males in soil $(250 \mathrm{~g})$ and females in roots $(1 \mathrm{~g})$ of $T$. semipenetrans were counted (Ahmed, 1974 and El-Deeb, 1995). Effects of inoculum levels of $T$. semipenetrans on some vegetative growth parameters of Volkameriana seedlings were determined: weight (Fresh and dry) and length of shoots and roots after one year of treatment. Data were subjected to analysis of variance (ANOVA) and averages of shoot and root weights and lengths as well as numbers of each nematode developmental stage were compared using Duncan's New Multiple Range Test. Nematode counts were log-transformed before ANOVA since $T$. semipenetranshas showed contagious distribution (Abd-Elgawad, 1992).

\section{Results}

Results in Table (1) showed development and reproduction of $T$. semipenetrans $\mathrm{J}_{2}$ and males in soil as well as female and egg mass numbers in roots of Volkameriana rootstocks at five initial inoculum levels. The final population density of $J_{2}$ and males in soil increased with increasing Pi from 5000 to $20000 \mathrm{~J}_{2}$ and males/pot, but such a steady increase did not hold true for $\mathrm{Pi} 25000$ nematodes/pot. Only the lowest final population $\left(P_{f}\right)$ density, 72343, was significantly $(P \leq 0.05)$ different from the other $P_{f}$ (Table 1). Similarly, the numbers of $T$. semipenetrans females increased with the increase in the inoculum level of citrus nematode from 5000 to $20000 \mathrm{~J}_{2}$ and males/pot, and then decreased at the inoculum level $25000 \mathrm{~J}_{2}$ and males/pot. Significant differences in female numbers were recorded between 5000, (10000 \& 15000), and (20000\& 25000) $\mathrm{J}_{2}$ and males/pot. Yet, the numbers of egg masses in citrus roots increased with increase in $\mathrm{Pi}$ up to $15000 \mathrm{~J}_{2}$ and males/pot, and then decreased. Significant differences were recorded in $P_{f}$ concerning egg mass numbers but such differences were not consistent with their corresponding inoculum levels. The total $P_{f}$ had more or less the same trend as mentioned above where the numbers increased up to inoculum level $20000 \mathrm{~J}_{2}$ and males/pot and then decreased [Fig. $1(\mathrm{~A})$ ]. The rate of build-up of citrus nematode was in the range 3.7 to 14.8 [Table 1 and Fig. 1 (B)]. The lowest rate of build-up was obtained with the inoculum level of $25000 \mathrm{~J}_{2}$ and males/pot, while the highest rate was obtained with initial level of $5000 \mathrm{~J}_{2}$ and males/pot. It is clear that the rate of build-up decreased with the increase in the nematode inoculum level.

The tested vegetative growth parameters of $C$. volkameriana were differently affected according to the nematode inoculum level (Table 2). Such levels gave shoot lengths in the range 73.9 to $101.3 \mathrm{~cm}$ compared to 119.8 in the control. The highest reduction (\%) of citrus shoot length (about $38.3 \%$ ) was obtained with the inoculum level of $20000 \mathrm{~J}_{2}$ and males/pot. 
Table (1): Development and reproduction of Tylenchulus semipenetrans in Citrus volkameriana at five nematode inoculum levels under greenhouse conditions.

\begin{tabular}{|c|c|c|c|c|c|}
\hline \multirow{3}{*}{$\begin{array}{l}\text { Inoculum } \\
\text { levels }\left(J_{2}\right)\end{array}$} & \multicolumn{3}{|c|}{ Nematode-developmental stages } & \multirow{3}{*}{$\begin{array}{c}\text { Final } \\
\text { population }\end{array}$} & \multirow{3}{*}{$\begin{array}{l}\text { Rate of } \\
\text { build up }\end{array}$} \\
\hline & \multirow{2}{*}{$\begin{array}{c}\mathrm{J}_{2} \text { and males } \\
\text { in soil }\end{array}$} & \multicolumn{2}{|c|}{ Roots } & & \\
\hline & & Females & Egg masses & & \\
\hline 5000 & $72343 b^{*}$ & $938 \mathrm{c}$ & $538 \mathrm{c}$ & 73819 & 14.8 \\
\hline 10000 & 87579 a & $1152 b$ & $713 a b$ & 89444 & 8.9 \\
\hline 15000 & $93050 \mathrm{a}$ & $1214 b$ & $820 \mathrm{a}$ & 95084 & 6.3 \\
\hline 20000 & $95515 \mathrm{a}$ & $1442 \mathrm{a}$ & $702 \mathrm{~b}$ & 97659 & 4.9 \\
\hline 25000 & $89290 \mathrm{a}$ & $1405 a$ & $626 \mathrm{bc}$ & 91321 & 3.7 \\
\hline
\end{tabular}

*Means in a column followed by the same small letter(s) are not significant at $\mathrm{P} \leq 0.05$ according to Duncan's new multiple-range test.

(A)

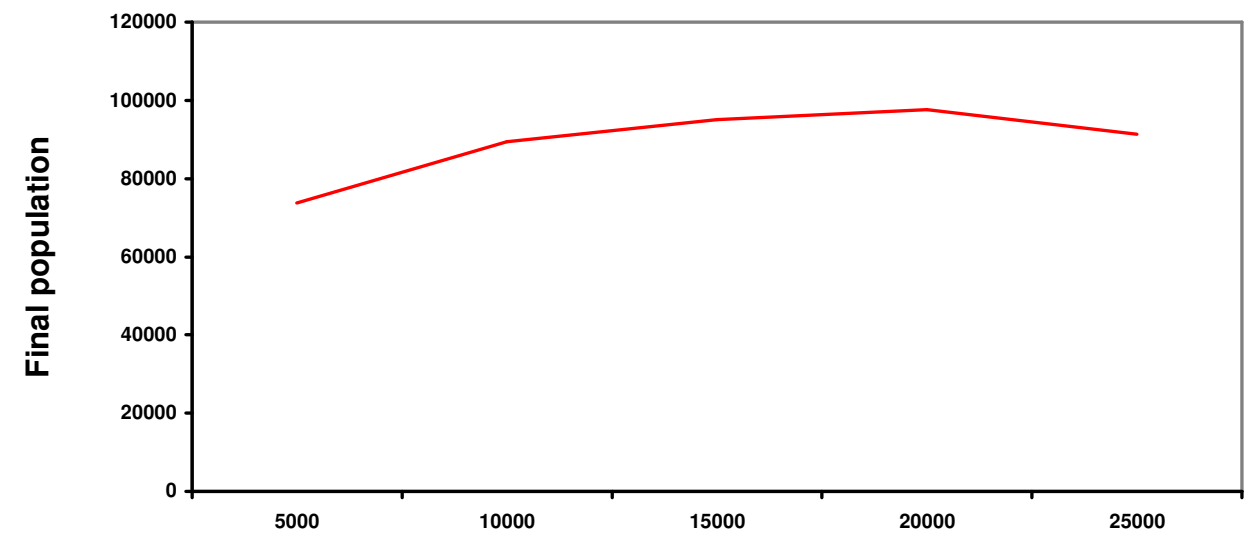

(B)

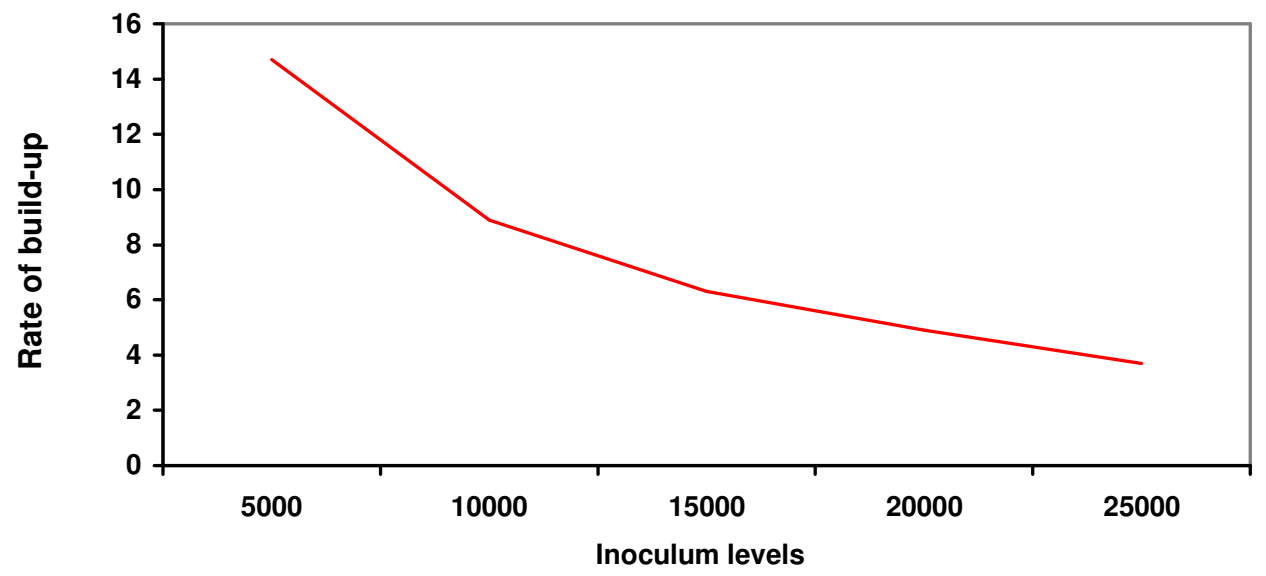

Fig. (1): Efficacy of five inoculum levels of Tylenchulus semipenetrans on the final populations (A) and rate of build-up (B) in Citrus volkameriana under greenhouse conditions. 
Table (2): Effect of five inoculum levels of Tylenchulus semipenetrans on some vegetative growth parameters in $C$. volkameriana under greenhouse conditions.

\begin{tabular}{|c|c|c|c|c|c|c|c|c|c|c|}
\hline \multirow[b]{3}{*}{$\begin{array}{l}\text { Inoculum } \\
\text { levels }\left(\mathrm{J}_{2}\right)\end{array}$} & \multicolumn{10}{|c|}{ Growth parameters } \\
\hline & \multicolumn{6}{|c|}{ Shoots } & \multicolumn{4}{|c|}{ Roots } \\
\hline & 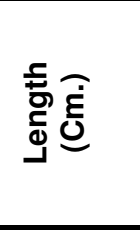 & 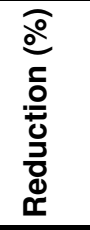 & 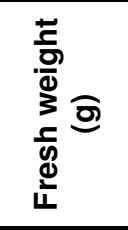 & 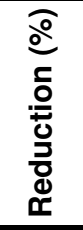 & $\begin{array}{l}\frac{ \pm}{5} \\
\frac{0}{0} \\
3 \\
\frac{1}{0}\end{array}$ & 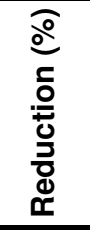 & 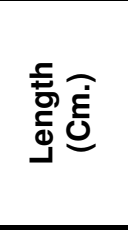 & 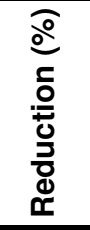 & 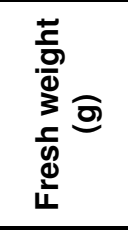 & 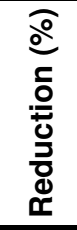 \\
\hline Control & $119.8 a^{*}$ & - & $78.8 \mathrm{a}$ & - & $31.7 \mathrm{a}$ & - & $76.8 \mathrm{a}$ & - & $109.3 \mathrm{a}$ & - \\
\hline 5000 & $101.3 b$ & 15.4 & $70.7 \mathrm{ab}$ & 10.2 & $21.2 b$ & 33.5 & $60.0 \mathrm{~b}$ & 21.8 & $95.8 \mathrm{ab}$ & 12.4 \\
\hline 10000 & $86.0 \mathrm{c}$ & 28.2 & $68.3 \mathrm{ab}$ & 13.3 & $18.1 \mathrm{bc}$ & 42.9 & $49.8 \mathrm{bc}$ & 35.2 & $88.5 \mathrm{bc}$ & 19.0 \\
\hline 15000 & $81.6 \mathrm{~cd}$ & 31.8 & $62.3 \mathrm{~b}$ & 20.9 & $17.5 \mathrm{c}$ & 44.7 & $56.0 \mathrm{bc}$ & 27.1 & $76.0 \mathrm{c}$ & 30.5 \\
\hline 20000 & $73.9 \mathrm{~d}$ & 38.3 & $58.4 \mathrm{~b}$ & 25.9 & $19.6 \mathrm{bc}$ & 38.2 & $53.6 \mathrm{bc}$ & 30.2 & $84.8 \mathrm{bc}$ & 22.4 \\
\hline 25000 & $75.5 d$ & 37.0 & $60.8 \mathrm{~b}$ & 22.8 & 20.6 bc & 35.0 & $49.1 \mathrm{c}$ & 36.0 & 81.2 bc & 25.7 \\
\hline
\end{tabular}

*Means in each column followed by the same small letter (s) are no significant at $\mathrm{P}<0.05$ according to Duncan's multiple-range test.

It is clear that the shoot length reduction (\%) increased with increase in the inoculum levels until $20000 \mathrm{~J}_{2}$ and males and then the reduction decreased. Significant differences were recorded in the shoot length between the control and nematode inoculum levels (Table 2) except between 15000 and $20000 \mathrm{~J}_{2}$ and males/pot and among15000, $20000 \& 25000 \mathrm{~J}_{2}$ and males/pot [Table 2 and Fig. 2 (A)]. The fresh weight of Volkameriana shoot was in the range 58.4 to $70.7 \mathrm{~g}$ with nematode inoculum levels from 5000 to $25000 \mathrm{~J}_{2}$ and males/pot, compared to 78.8 $\mathrm{g}$ in the control. The highest reduction (\%) of fresh weight was $25.9 \%$ obtained with $20000 \mathrm{~J}_{2}$ and males/pot. The fresh weight of citrus shoot had the same trend of shoot length results (Table 2). Significant differences in the fresh weight of citrus shoot were recorded from the inoculum level 15000 onward [Table 2 and Fig. 2 (B)]. The dry weight of citrus shoot was in the range 17.5 to $21.2 \mathrm{~cm}$, compared to 31.7 $\mathrm{cm}$ in the control. The inoculum level of $15000 \mathrm{~J}_{2}$ and males/pot gave the highest reduction (\%) in shoot dry weight $(44.7 \%)$. Significant differences in such weights were recorded between the control treatment and each of nematode inoculum level. In this growth parameter, significant difference was also recorded between 5000 and $15000 \mathrm{~J}_{2}$ and males/pot [Table 2 and Fig. 2 (C)]. 
(A)

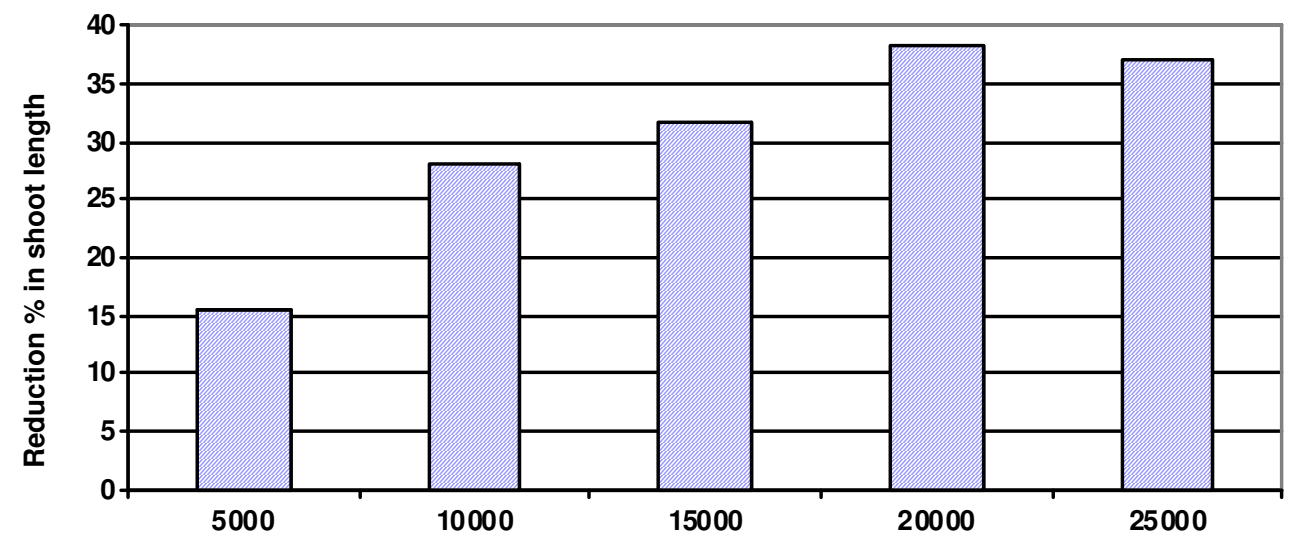

(B)

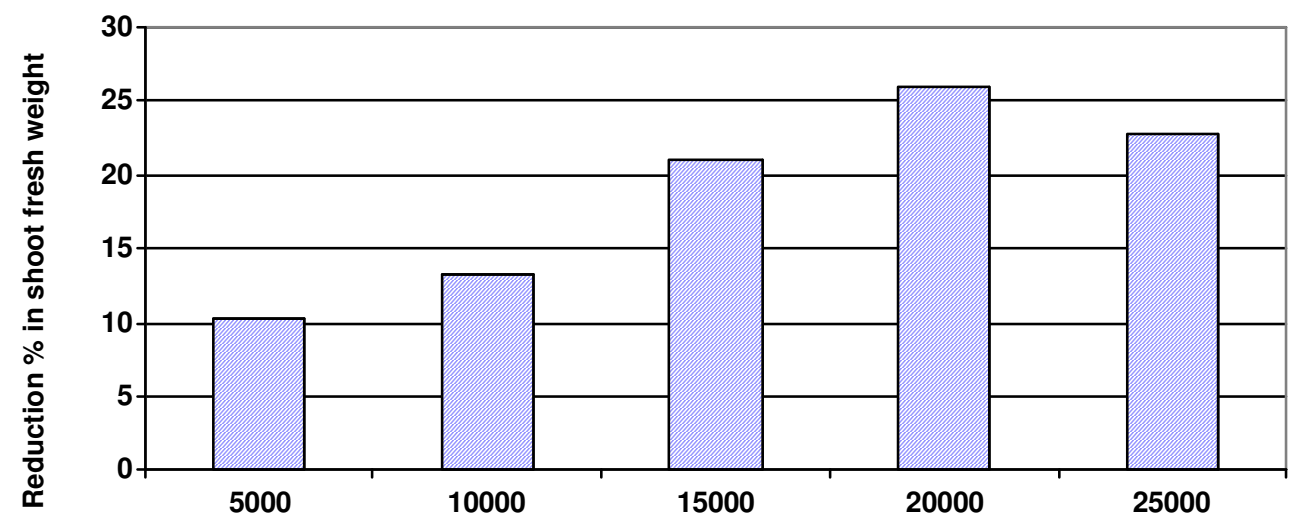

(C)

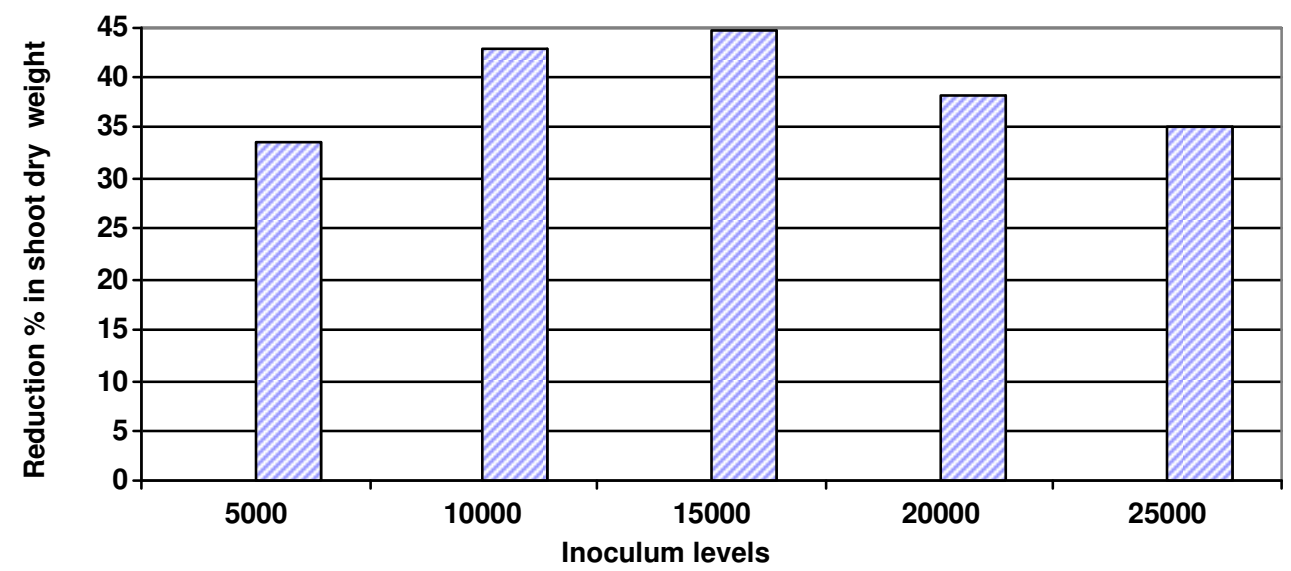

Fig. (2): Efficacy of five inoculum levels of Tylenchulus semipenetrans on growth parameters of shoots, i.e. length $(A)$, fresh weight $(B)$ and dry weight $(C)$ in C. volkameriana, under greenhouse conditions. 
The length and fresh weight of citrus roots were generally affected by the nematode inoculum levels, compared to the control treatment (Table 2). The length of roots was in the range 49.1 to $60.0 \mathrm{~cm}$, compared to $76.8 \mathrm{~cm}$ in the control. The highest reduction of root length (36\%) was obtained with inoculum level of $25000 \mathrm{~J}_{2}$ and males/pot. Significant differences were recorded between the control treatment and each inoculum level concerning the root length. Also, significant differences were recorded between inoculum levels of 5000 and $25000 \mathrm{~J}_{2}$ and males/pot [Table 2 and Fig. $3(\mathrm{~A})$ ]. The fresh weight of Volkameriana roots ranged from 70.0 to 59.8 $\mathrm{g}$ with different inoculum levels, compared to $109.5 \mathrm{~g}$ in the control (Table 2). The highest root fresh weight reduction $(30.5 \%)$ was obtained with inoculum level of $15000 \mathrm{~J}_{2}$ and males/pot [Fig. $3(\mathrm{~B})$ ].

(A)

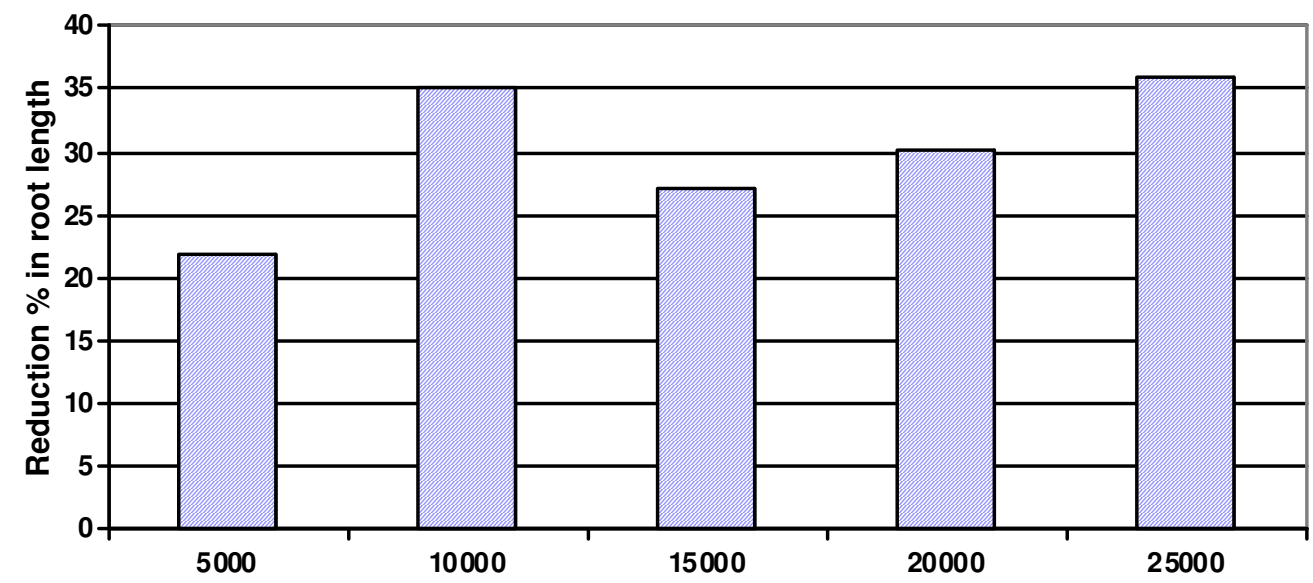

(B)

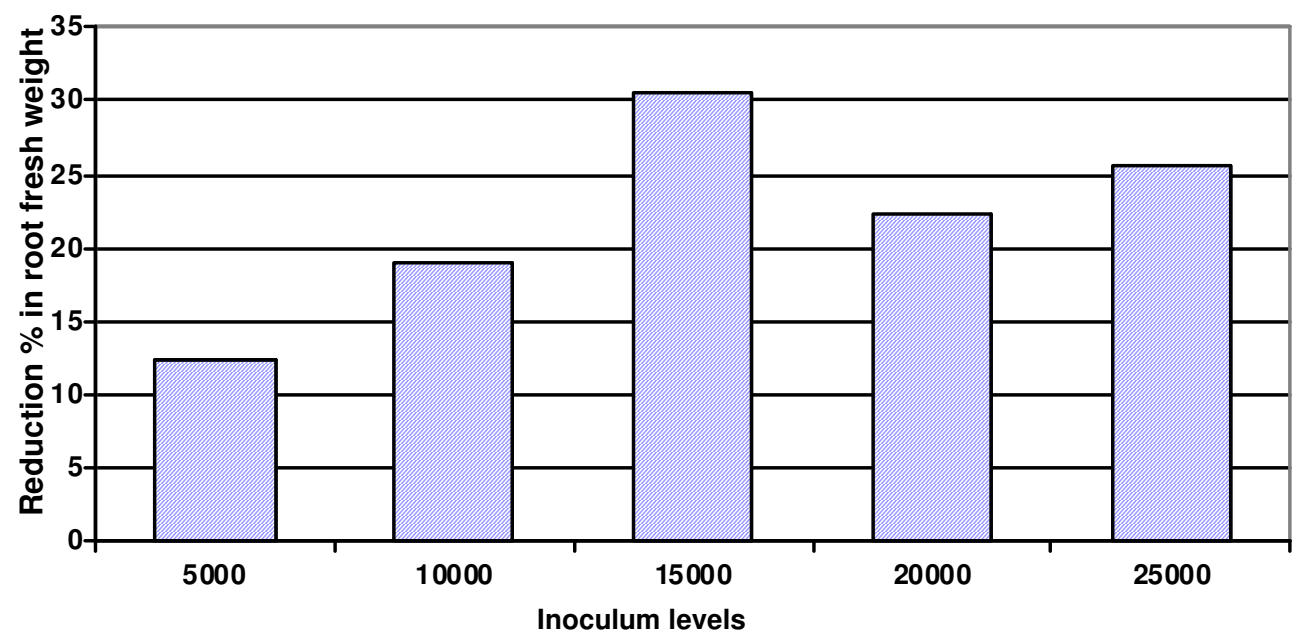

Fig. (3): Efficacy of five inoculum levels of Tylenchulus semipenetrans on some growth parameters of roots, i.e. length $(A)$ and fresh weight $(B)$ in $C$. volkameriana, under greenhouse conditions. 


\section{Discussion}

The reluctance of nurserymen in Egypt to move the nurseries to sites that can produce nematode-free planting material and the tendency of growers to mulch virgin soil with infested soil from the Nile Valley (Abd-Elgawad and McSorley, 2009), have mainly created the citrus nematode problem in citrus groves of newly reclaimed land. Therefore, $T$. semipenetruns is the most frequent and abundant plant-parasitic nematode that occurs in Egyptian citrus orchards (Abd-Elgawad et al., 2010). Furthermore, Volkameriana roots inoculated with T. semipenetrans before inoculation with Fusarium solani resulted in increasing susceptibility of this rootstock to Fusarium root rot disease in Egypt (El-Mohamedy and Hasabo, 2005). It is assumed that with the usual build up of $T$. semipenetrans populations over time, the nematode may cause different degrees of citrus damage depending on their densities proportional to our results (Table 2; Figs 2 and 3) where the nematode numbers were obviously greater outside the roots, in soil, than in/on the roots at all levels (Table 1). Other different inoculum levels were used in previous $T$. semipenetrans studies. In Egypt, Afia (1997) investigated behavior and reproductive potential of three, citrus, olive and persimmon, biotypes of $T$. semipenetrans as affected by host stress and inoculation levels. He used as high as 16000 juveniles/pot whereas El-Nouby (2002) used levels up to 8000 juveniles/seedling to evaluate the response of eight rootstock cultivars to $T$. semipenetrans. In Spain, Verdejo-Lucas et al. (1997) used up to 160000 eggs + juveniles/plant to identify optimal inoculum densities for screening hybrid citrus rootstocks for resistance to $T$. semipenetrans. The maximum level used in our study falls within the above-mentioned levels (Tables 2). Verdejo-Lucas et al. (1997) concluded that an initial inoculum level of $1 \times 10^{4}$ eggs $+\mathrm{J} 2$ per plant was sufficient for such greenhouse screening of citrus rootstocks, since enough adult females and eggs were produced per plant after six months to evaluate resistance. They reported that high inoculum levels tested produced the maximum numbers of females and eggs, but the amount of roots needed to provide such inoculum was far too high to be of practical use. Furthermore, they stressed that artificially high inoculum levels may affect plant response and may not be field relevant. Numerous surveys in Egypt (e.g., bd-Elgawad, 1995; Korayem, and Hassabo. 2005; Ibrahim et al., 2010; Abd-Elgawad et al., 2011) and elsewhere (e.g., Duncan et al., 1989 and 1995; Verdejo-Lucas et al., 1995; Sorribas et al., 2008) have shown that population densities of $T$. semipenetrans were much lower than $1 \times 10^{4}$ eggs $+\mathrm{J}_{2}$ per gram of root in most citrus orchards sampled. Females, eggmasses and $\mathrm{J} 2$ recovered from the highest inoculum level (25000 J2 and males/seedling) in our study were lower than expected (Table 1) for unknown reasons. Yet, the rate of nematode increase can be affected by the experimental conditions, including the method of inoculation, pot size and potting mixture (Van Gundy and Tsao, 1963; O'Bannon, 1968; Niles et al., 1995; and Verdejo-Lucas et al., 1997). Our results 
agreed with others (Afia, 1997; El-Nouby, 2002) since T. semipenetrans population succeeded in reproducing on its citrus host at any level of nematode initial inoculation (Table 1). Moreover, the nematode final population proportionally increased as the inoculation level increased except at the highest inoculum level. It is possible that nematode competition, at such highest inoculum level, per space unit of the roots, was so high that it could adversely affect the infectivity (females per gram root) and reproductive potential (eggs $+\mathrm{J} 2 / \mathrm{g}$ root) as well as final nematode population. On the other hand, nematode-rate of build up always decreased as the inoculation level increased which coincides with other reports (e.g., Afia, 1997; El-Nouby, 2002). In other cases, a high nematode rate of build up was observed especially after applying nematicides against some plant-parasitic nematode species. Such an unexpected increase in nematode numbers may be due to faulty application of nematicides, insufficient chemical, and unfavorable weather conditions.

According to the obtained results of the different $T$. semipenetrans inoculum levels, $T$. semipenetrans population increase per nematode added was proportional to the amount of both citrus shoot fresh weight and length measured except the highest inoculum level (Table 2). This proportionality held true for shoot dry weight except in the highest two inoculum levels. Root fresh weight followed the same trend of shoot dry weight in response to different inoculum levels. It is possible that roots produced at the highest inoculum levels were probably insufficient to support the highest nematode numbers. Yet, reduction in root length followed a unique trend. It increased from 5000 to $10000 \mathrm{~J}_{2}$ and males $/ 250 \mathrm{~g}$ soil then decreased from 15000 to $20000 J_{2}$ and males $/ 250 \mathrm{~g}$ but the most reduction was attained at the highest inoculum level (Table 2). In general, nematode reproduction and host damage were both affected by the initial inoculum levels which coincided with other reports concerning the role of different inoculum levels of plant-parasitic nematodes.

\section{Acknowledgements}

This research was supported in part by In-House project No. 10120604 Entitled "Integrated management of nematode pests and pre- and post-harvest diseases of economically important crops" and USA-Egypt fund project No. 338.

\section{References}

Abd-Elgawad, M. M. (1992). Spatial distribution of the phytonematode community in Egyptian citrus groves. Revue De Nematologie 14:367-373.

Abd-Elgawad, M.M. (1995). Estimate of (Naval) orange yield loss in Tylenchulus semipenetrans-infested groves. Egyptian Journal of Applied Science, 10: 6-14.

Abd-Elgawad, M. M. M. and R. McSorley (2009). Movement of citrus nematodeinfested material onto virgin land: detection, current status and solutions with cost-benefit analysis for Egypt. Egyptian Journal of Agronematology 7(1):35-48. 
Abd-Elgawad, M.M., Al-Yahya, F.A. and Stephan, Z.A. (2010). Nematodes of citrus (In Arabic), In : "Plant Nematodes in Arab Countries" W.A. AbuGharbieh, A.S. Al-Hazmi, Z.A. Stephan and A.A. Dawabah (Eds). Darwael for publishing, Arab Society of Plant Protection, Amman, Jordan. Pp. 553602.

Abd-Elgawad, M. M. M., Duncan, L. W., Koura, F. H. F., Abd El-Wahab, A. E., Montasser, S. A., and Hammam, M. M. A. (2011). Management revision and observations on Tylenchulus semipenetrans on citrus yield in Egypt. Egyptian Journal of Agronematology 10(1):64-77.

Afia, A.I.B. (1997). Host preference and biotype detection of citrus nematode, Tylenchulus semipenetrans in Egypt. Ph. D. thesis, Fac. of Agric., Cairo University, Egypt. pp. 110.

Ahmed, S.S. (1974). Ecological and biological studies on the citrus nematode Tylenchulus semipenetrans. M. Sc. Thesis, Fac. Agric., Cairo Univ., pp. 53.

Duncan, L.W. (2005). Nematode parasites of citrus. In: Luc, M.; Sikora, R.A.; and Bridge, J. (Eds). Plant Parasitic Nematodes in Subtropical and Tropical Agriculture, $2^{\text {nd }}$ edition: Wallingford, U. K. CABI Publishing, 437-466.

Duncan, L. W., Ferguson, J. J., Dunn, R. A. and Noling, J. W. (1989). Application ofTaylor's power law to sample statistics of Tyknchulus semipenetrans in Florida citrus. Journal of Nematology (Supplement) $21: 707-711$.

Duncan, L.W., P. Mashela, J. Ferguson, J. Graham, M. M. Abou-Setta and M. M. El-Morshedy (1995). Estimating crop loss in orchards with patches of mature citrus trees infected by Tylenchulus semipenetrans. Nematropica 25:43-51.

El-Deeb, A.A.A. (1995). Studies on citrus nematode Tylenchulus semipenetrans on certain orchards in Sharkia governorate. Ph.D. Thesis, Fac. Agric., Zagazig University, Egypt. pp. 165.

El-Mohamedy, R.S.R. and Hasabo, S.A. (2005). Response of some citrus rootstocks to infection with Fusarium solani and citrus Nematode Tylenchulus semipenetrans under greenhouse conditions. Egyptian Journal of Phytopathology 33(2): 11-25.

El-Nouby, A.S.M.M. (2002). Citrus nematode problems, new approaches for its control in newly reclaimed lands. M. Sc. thesis, Fac. of Agric., Cairo University, Egypt.

Hafez, O.M. (2006). Evaluation of growth characteristics of some citrus rootstocks using finger print technique. American-Eurasian Journal of Agricultural \& Environmental Sciences 1(3): 243-248.

Ibrahim, A.M. and Khaleef, M.N.H. (1997). The citrus: cultivation, care, and production (In Arabic) p. 718. Monshaat Almaarf, Alexandria, Egypt.

Ibrahim, I.K.A.; Mokbel, Asmaa, A. and Handoo, Z.A. (2010). Current status of phytoparasitic nematodes and their host plants in Egypt. Nematropica, 40:239-262. 
Kaplan, D.T. and O'Bannon, J.H. (1981). Evaluation and nature of citrus nematode resistance in swingle citrumelo. Proc. Fla. State Hort. Soc. 94:3336.

Korayem, A.M., and Hassabo, Susan, A.A. (2005). Citrus yield in relation to Tylenchulus semipanetrans in silty loam soil. International Journal of Nematology 15(2): 179-182.

Sorribas, F.J., Verdejo-Lucas, S., Pastor, J., Ornat, C., Pons, J., and Valero, J. (2008). Population densities of Tylenchulus semipenetrans related to physicochemical properties of soil and yield of clementine mandarin in Spain. Plant Disease 92:445-450.

Verdejo-Lucas, S., Sorribas, F.J., Pons, J., J. B. Forner, J.B. and Alcaide, A. (1995). Niveies poblacionalcs del nematodo Tylenchulus semipenetrans ea piantadones de cftrieos. IV Congreso Soc. Espauola Ciencias Hort., Barcelona, Spain, 238. (Abstr.).

Verdejo-Lucas, S.; Sorribas, F.J.; Forner, J.B. and Alcaide, A. (1997). Screening hybrid citrus rootstocks for resistance to Tylenchulus semipenetrans Cobb. HortScience 32(6): 1116-1119.

Young, R.W. (1954). An incubation method for collecting migratory endoparasitic nematodes. Plant Disease Reporter 38:794-795. 


\section{الملخص العربي}

تأثير العدوى بمستويات مختلفة من نيماتودا تيلنكيولس سميبنترانس على مدي تطور النيماتودا وتكاثرها وضررها علي شتلات موالح الفولكا ماريانا

محفوظ محمد مصطفى عبد الجواد*، فايقة فهمي حسن قورة*، أحمد عصام عبد الوهاب***، حسن عبد الخير*،

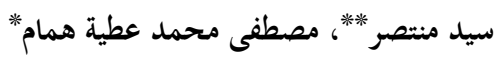
*قم أمراض النبات - المركز القومي للبحوث - الدقي r r Y r I - القاهرة - مصر. قـ****قم الحيوان والنيماتولوجيا الزراعية - كلية الزراعة - جامعة الأزهر - القاهرة - مصر.

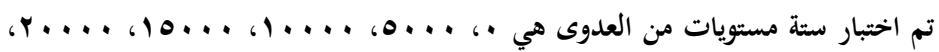

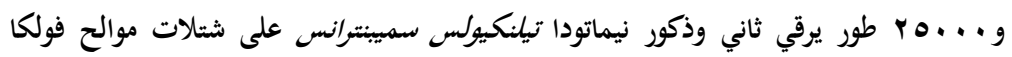

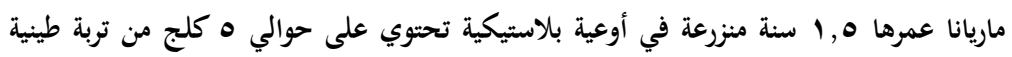

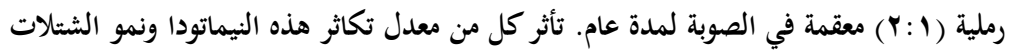

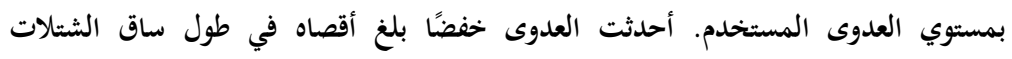

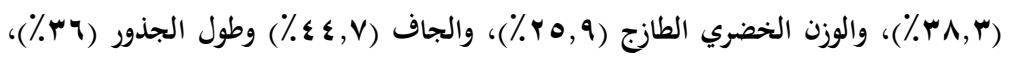

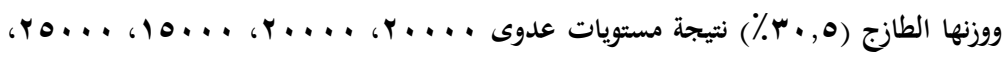

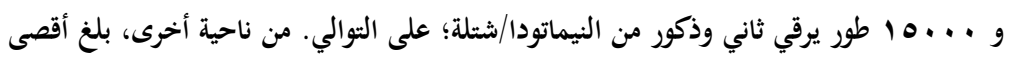

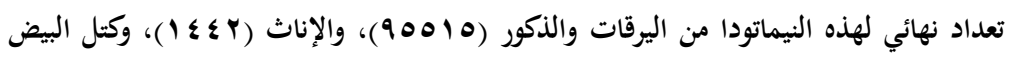

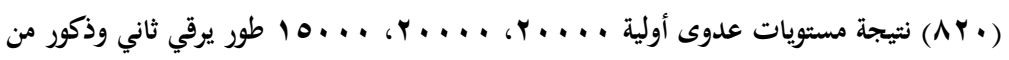

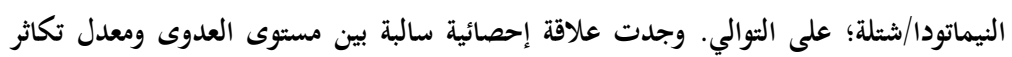
النيماتودا. 